\title{
Impact of an educational program on earthquake awareness and preparedness in Nepal
}

\author{
Shiba Subedi ${ }^{1}$, György Hetényi ${ }^{1}$, and Ross Shackleton ${ }^{2}$ \\ ${ }^{1}$ Institute of Earth Sciences, Faculty of Geosciences and Environment, University of Lausanne, Lausanne, Switzerland \\ ${ }^{2}$ Institute of Geography and Sustainability, Faculty of Geosciences and Environment, University of Lausanne, \\ Lausanne, Switzerland
}

Correspondence: Shiba Subedi (shiba.subedi@unil.ch)

Received: 7 April 2020 - Discussion started: 20 April 2020

Revised: 31 July 2020 - Accepted: 17 August 2020 - Published: 22 September 2020

Abstract. Scientific education of local communities is key in helping to reduce the risk associated with natural disasters such as earthquakes. Western Nepal has a history of major seismic events and is highly prone to further earthquakes; however, the majority of the population is not aware about or prepared for them. To increase earthquake awareness and improve preparedness, a seismology education program was established at 22 schools in Nepal. At each school, educational activities were performed by teaching earthquakerelated topics in classrooms, offering training to teachers and through installing a low-cost seismometer network which supported both teaching and awareness objectives. To test the effects of this program, we conducted two surveys with school children, one before and one after the initiation of the program, with several hundred participants in each. The survey findings highlighted that educational activities implemented at schools are effective in raising the awareness levels of children, promoting broader social learning in the community, thus improving the adaptive capacities and preparedness for future earthquakes. However, perceptions of risk did not change very much. The high and positive impact of the program on the students and the community is encouraging for the continuation and expansion of the program.

\section{Introduction}

It is becoming increasingly important to educate people in the era of global change about environmental hazards to ensure that they are well prepared to face the rising number of challenges. Education may play a central role in the risk man- agement of natural hazards and may help to reduce vulnerability and improve adaptability though allowing people to anticipate and prepare for hazards (Godschalk, 2003; IRGC, 2005).

Exact earthquake prediction is currently not possible, but responses to such events can be prepared for, in advance, to mitigate the effects they can have on society and human wellbeing (Turner, 1976). The impacts of earthquake disasters can be minimized by learning what to do before, during and after earthquakes and by taking a variety of personal safety measures (Lehman and Taylor, 1987). Whether people prepare for future earthquakes or not can be significantly influenced by their education and their engagement with the topic (Tanaka, 2005). All-inclusive public awareness and education is fundamental for reducing casualties, personal injuries and property damage from natural disasters (National Research Council, 1991; Torani et al., 2019). Researchers can contribute to and play a key role in the education of society, not just to engage more people in research but also to provide scientific explanations for natural hazards and related consequences to local communities as well as helping to develop polices for mitigation of the effects.

Earthquakes are the most common and deadliest natural hazard in Nepal, with a long history of impacts in the country (Bollinger et al., 2016). Historical records indicate that many houses and temples in Nepal collapsed during the 1255 earthquake, and one-third of the population including the king, Abhaya Malla, was killed. There are also records of an earthquake with a moment magnitude $\left(M_{\mathrm{w}}\right)$ of $>8$ in 1505 (Ambraseys and Jackson, 2003) and indications that even larger earthquakes are plausible in the Himalayas 


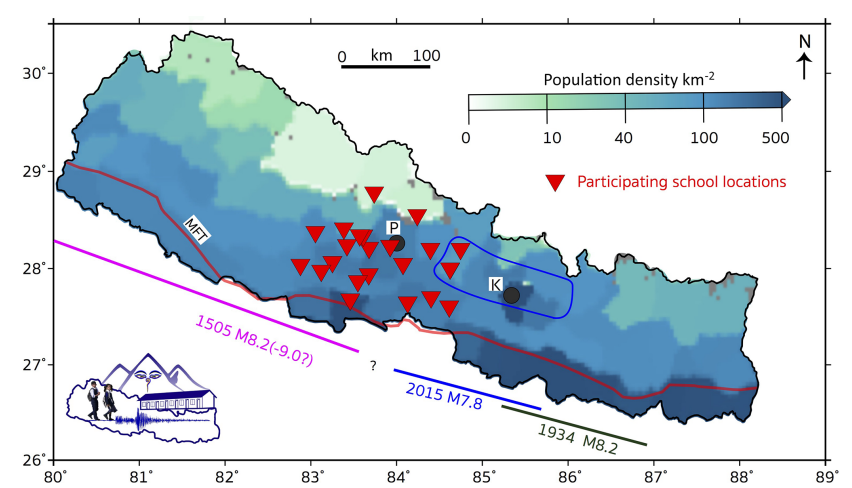

Figure 1. Map of Nepal, with the locations of the schools participating in the Seismology at School in Nepal program. The background represents population density data (CIESIN and CIAT, 2005). The Main Frontal Thrust (MFT), the surface trace of the fault underlying most of Nepal and hosting all great earthquakes in the region, is indicated with a red solid line. Three colored segments represent the rupture extent of the corresponding major and great earthquakes with moment magnitude $\left(M_{\mathrm{W}}\right)$, as indicated (after Bollinger et al., 2016). For the 2015 Gorkha earthquake, the rupture area is also plotted (blue contour). The letters $\mathrm{P}$ and $\mathrm{K}$ refer to cities of Pokhara and Kathmandu, respectively, marked with black circles.

(Stevens and Avouac, 2016). In 1934, during an earthquake (Fig. 1) with a $M_{\mathrm{w}}$ of 8.2 , over 8500 people lost their lives, 200000 houses were severely damaged and more than 80000 buildings completely collapsed (Dixit et al., 2013). The most recent major earthquake $\left(M_{\mathrm{w}} 7.8\right)$ in 2015 hit central Nepal, resulting in about 9000 casualties, and nearly 800000 buildings were damaged or destroyed, leaving millions of people homeless. The resulting losses were equivalent to $50 \%$ of total national GDP (Chaulagain et al., 2018). In addition, 19000 classrooms were destroyed and 11000 damaged (NPC, 2015). It is suggested that if people had better awareness, preparations could have been more adequate and the negative impacts might have been reduced (Hall and Theriot, 2016).

In Nepal, the National Seismological Center under the Department of Mines and Geology has been conducting seismic monitoring since 1978. The Department of Education is responsible for developing different educational activities across the nation, and the Department of Urban Development and Building Construction has been working on building codes design and implementation. After the 2015 earthquake, the National Reconstruction Authority was established, and it works towards the reconstruction of buildings damaged during the Gorkha earthquake. Despite these efforts, the topic of earthquakes is not included at any level of the official school curriculum in the Nepali education system. However, recently the National Society for Earthquake and Technology (NSET) initiated the public School Earthquake Safety Program (SESP) in Nepal but only in a few districts of the country (Dixit et al., 2014). This program focuses mainly on

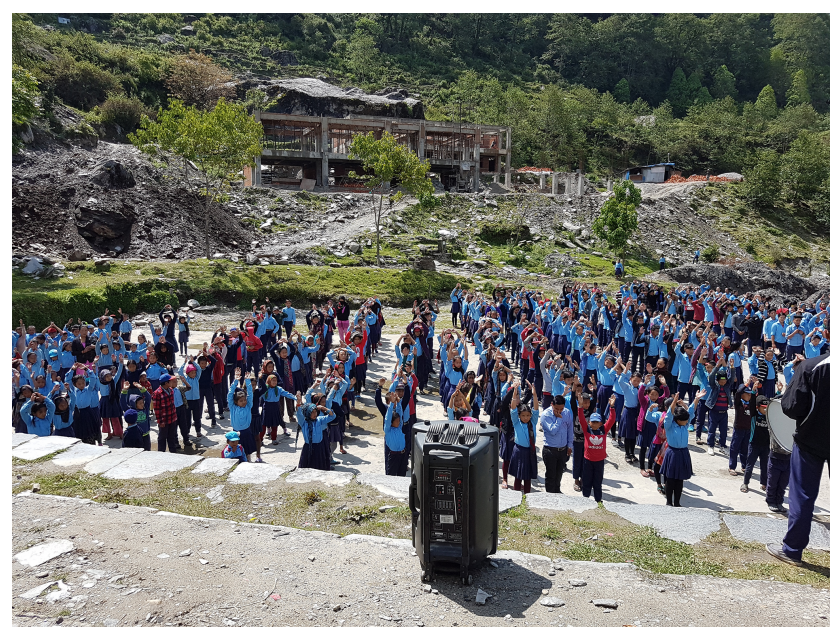

Figure 2. Students gathered for the morning assembly at the Shree Himalaya Secondary School, Barpak, Gorkha district in May 2018. The school building was damaged during the 2015 earthquake, and students were in temporary shelters. The construction of the new building is visible at the top of the picture. (Photo: Shiba Subedi, with the permission of the school.)

the retrofitting of school buildings to restore them, and minimize future damage, following the 2015 earthquake; however, educational efforts are still very limited.

Following the devastating 2015 Gorkha earthquake event, and considering the history of major earthquakes and the likelihood of many more as well as the poor educational efforts on the topic, we initiated and implemented a seismology education program in schools in western Nepal (Fig. 1; Subedi et al., 2020), including the area affected by the 2015 earthquake and expanding towards the west (Fig. 2). The aim of the program is to increase earthquake awareness levels in Nepal, starting from the schools, with the hope that this knowledge will be spread into the community, mostly through social learning and partly through the establishment of a low-cost seismic network (Figs. 1 and 3). In this study, the effects of the education program for earthquake awareness and preparedness are evaluated. The evaluation was performed by collecting data from students through two surveys, one before and one after the initiation of the education program.

\section{Methods}

The data for this study were collected using two questionnaire surveys, on paper, conducted in Nepali language in 2018 , before the initiation of the education program, and in 2020 , nearly 1 year after the full implementation of the program.

Before the initiation of the education program, we undertook fieldwork to help inform our strategy and the educational materials and to ensure that the education program was 


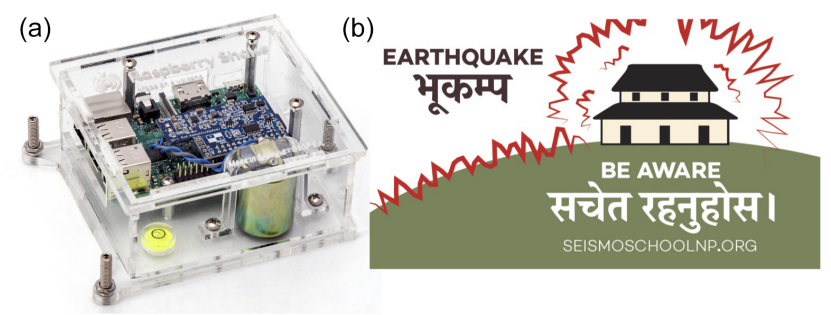

Figure 3. (a) The Raspberry Shake 1D low-cost seismometer, installed in 22 schools across central Nepal (see Fig. 1). (b) Earthquake awareness sticker, as a reminder, in English and the Nepali language (artwork of Mathias Dessimoz). The sticker's image is available for download from our program's web page at http://www. seismoschoolnp.org (last access: 18 September 2020).

well adapted to the Nepali education system. In 2018, during the first visit to schools, we talked with the school leaders about the program and its benefits and gave sample lectures (ca. 1-2 h, including questions) to students between the ages of 14 and 16, providing key information on earthquakes. Before the sample lecture, and in each school, students were requested to complete a paper questionnaire on earthquakerelated questions. In special lectures we also taught students how to prepare before an earthquake, how to save lives during an earthquake and what to do after an earthquake. We also provided a flyer, containing detailed information and pictures (Fig. 4), of which we distributed 500 copies. Similarly, we designed a sticker to remind people about earthquake hazards (Fig. 3) and distributed the stickers to students and teachers (3000 so far).

In April-May 2019, during the second school visit, the program was fully implemented with the installation of an educational, low-cost seismometer in every school. The seismometer's record is displayed on a computer, which is easily accessible to students in their physics class or through an online application. During the visit, we also identified an open place near the school where students should meet in case of an earthquake and installed an emergency meeting point sign in the Nepali language. To increase the efficiency of the learning and to ensure long-term uptake, we organized a $2 \mathrm{~d}$ workshop for nearly 100 school teachers, which was very well received. The full details of the program are documented in an earlier paper (Subedi et al., 2020) and all the material is accessible on the program website (http://www.seismoschoolnp.org).

In this article, we focus on evaluating the efficiency of our program in terms of improved knowledge related to increased awareness and change in behavior of students related to the preparedness for earthquakes. Out of the 22 schools participating in the program, 15 schools were chosen for the survey, covering a range of socioeconomic contexts. Students for the surveys were selected randomly from grades 9 and 10, representing the 14-16-year-old age group. The total number of responses collected was 318 and 480 in 2018 and 2020, re- spectively. For logistical reasons, some responses in the preand post-surveys (27\%) came from different schools, but this is not expected to affect the results as they were independent samples. While the first set of students surveyed had received no earthquake education whatsoever, those who filled out the second survey were frequently exposed to information and lectures about earthquakes from the teachers who were trained in our program.

When the exact same question was asked before and after our program's implementation, we quantified the change using $\chi^{2}$ test analysis. In doing so, our null hypothesis $\left(H_{0}\right)$ is that our program had no effect on the students. If this null hypothesis is unconfirmed (i.e., the $\chi^{2}$ value is above the threshold for the corresponding number of possible answers, and the respective $p$ value is below $5 \%$ ), then we conclude that the program had an effect on the students as their answers show a clear, statistically significant change. The complete set of questionnaires is available in the Supplement.

\section{Results}

The first measurement of this study, performed in the 2018 survey, was about the experience of the 2015 Gorkha earthquake. The majority of respondents, $94 \%$, felt the shaking. As the earthquake was on Saturday, schools were closed and students were at home. A total of $71 \%$ of students answered that they ran out of a building, and only $15 \%$ hid under a table; $8 \%$ did not know what to do, $3 \%$ stood next to a wall or a doorframe and $3 \%$ had other reactions.

\subsection{Knowledge about the causes and possibility of earthquakes in Nepal}

Before the implementation of the program, $7 \%$ of students believed that earthquakes were caused by a moving fish carrying the Earth (a Hindu belief and myth). However, $64 \%$ still chose the correct scientific answer of plate tectonics. The majority of students, $84 \%$, chose the plate tectonics answer in 2020, and the percentage of responses relating to the cultural and/or religious reasons dropped to $2 \%$ (Fig. 5).

Regarding the probability of a future earthquake greater than that in 2015, more students knew that such an earthquake in their region was quite likely after the education program (Fig. 6a). At the same time, there was a clear drop in the number of responses for very unlikely (17\% in 2018 to $5 \%$ in 2020) and a slight drop in the percentage of students answering that a future great earthquake is impossible.

Relating to the effects of a $M_{\mathrm{w}}>8$ earthquake, after the program, the answer of "I could die" increased by a factor of 1.8, and all other answers (i.e., I could be buried alive, I could get hurt, I could lose friends and my home could collapse) increased by a factor of at least 1.3 compared to 2018 (Fig. 6b; multiple answers were possible).

In $2018,31 \%$ of students answered they know when an earthquake will occur, which reduced to $11 \%$ in 2020 . The 


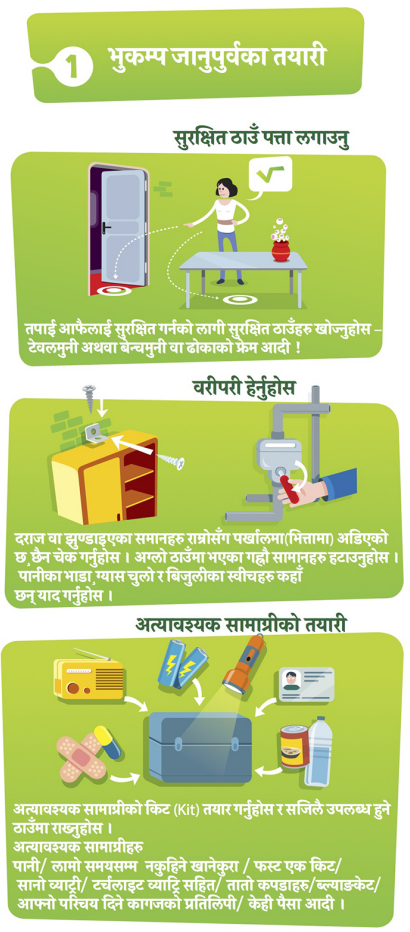

आफैले अभ्यास गर्नुहोस/ तालीम लिनुहोस

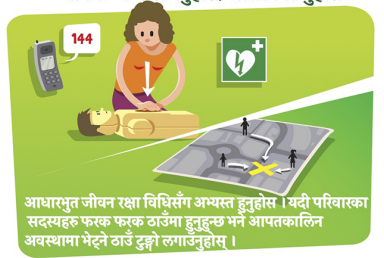

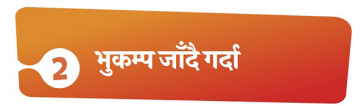

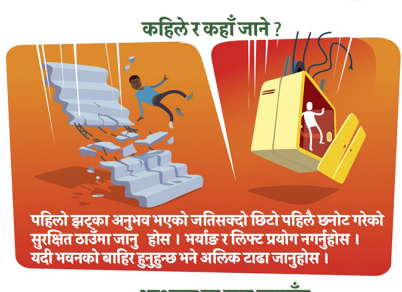

आश्रयस्थल पत्ता लगाउँनु

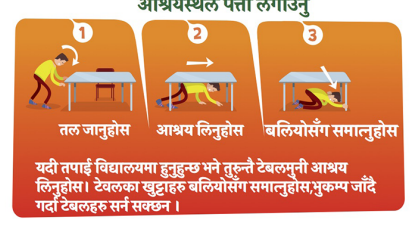

भवन बाहिरको जोखिम

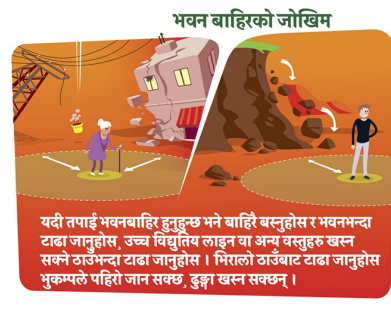

कारभित्र/बसभित्र

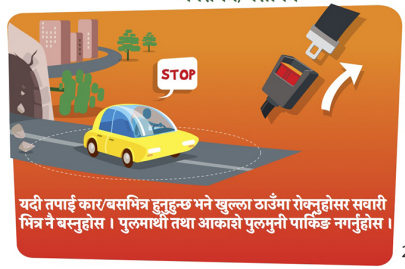

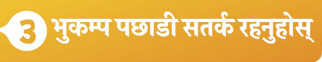

भुकम्पको झड्का सकिदा बित्तिके

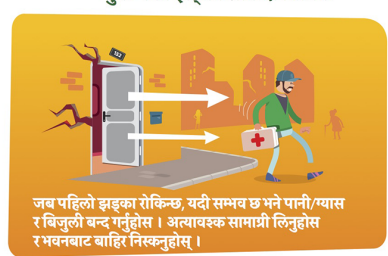

सावधानीपूर्वक बस्नुहोस

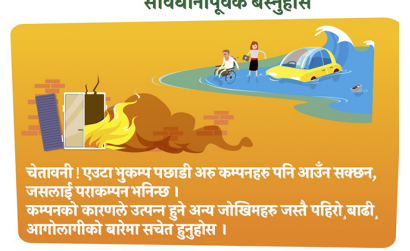

मेडिकल केयरको सुनिश्चित गर्नुहोस।

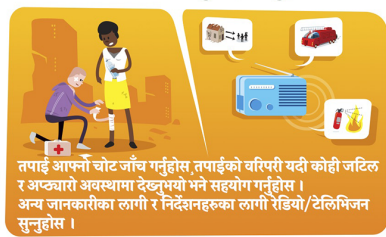

अत्यावश्यक सेवाहरु

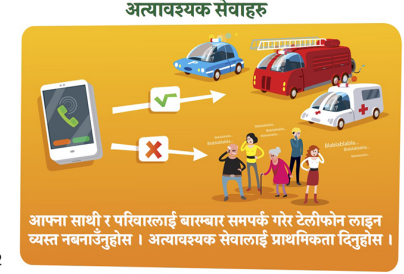

Figure 4. Educational flyer in the Nepali language on what to do before, during and after an earthquake. The flyer has been translated and adapted from an English version compiled by and available from the Centre for Earthquake Prevention (CPPS) earthquake education center in Sion, Switzerland (http://www.cpps-vs.ch, last access: 18 September 2020). The Nepali flyer is available for download from our program's web page at http://www.seismoschoolnp.org.

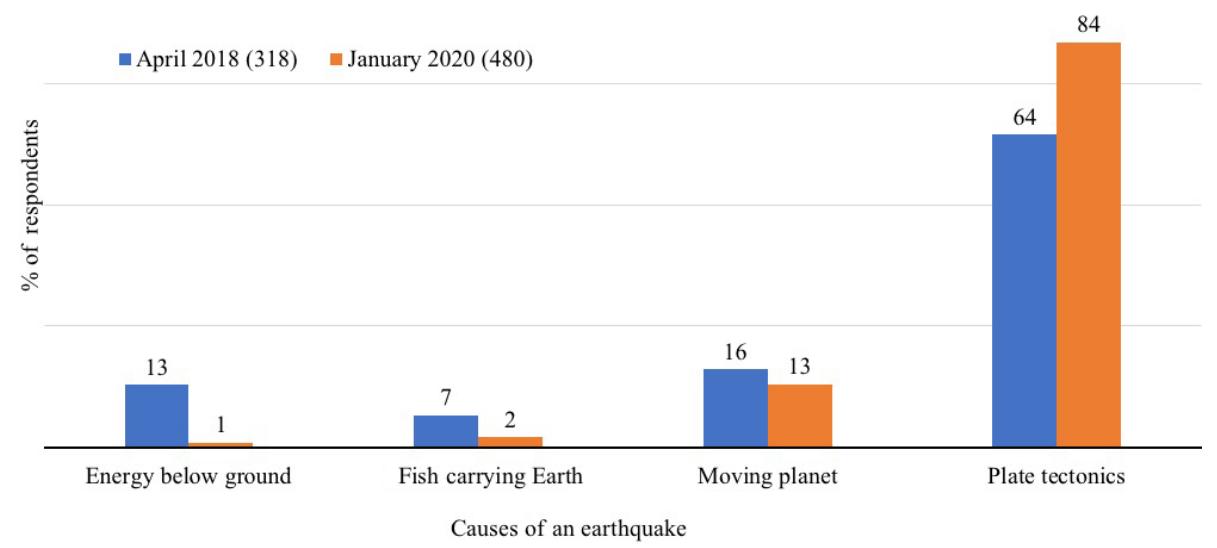

Figure 5. Student opinions on what causes earthquakes (Q1), before and after the initiation of our education program. $\left(\chi^{2}=78.15, p\right.$ value $=<0.00001$; the change is significant.) 
(a)
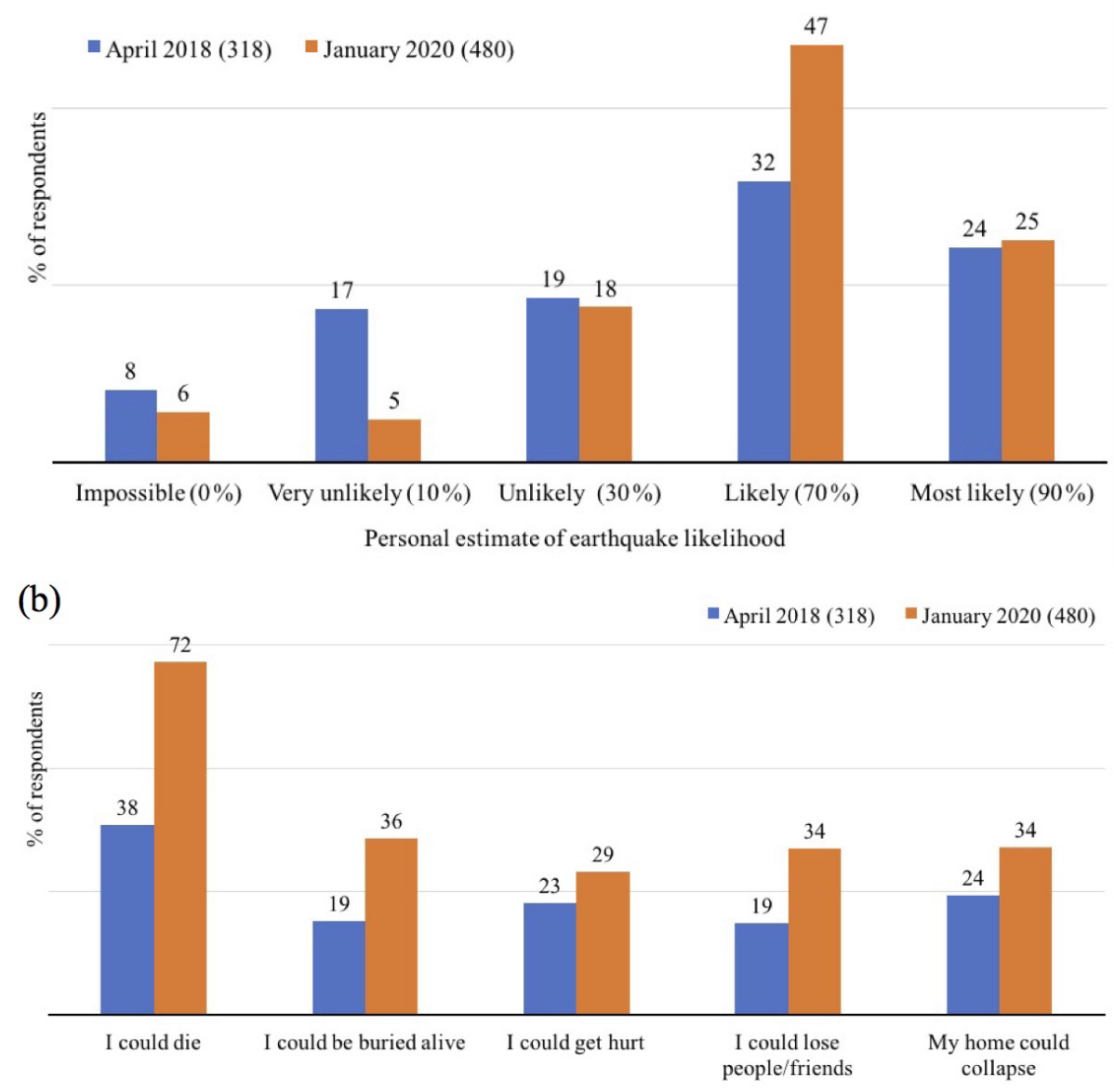

Personal idea on the potential effect of a future earthquake*

Figure 6. (a) Student views on how likely the occurrence of another earthquake bigger than the 2015 Gorkha earthquake is (Q3), before and after the initiation of our education program $\left(\chi^{2}=43.59, p\right.$ value $=<0.00001$; the change is significant.). (b) Student answers on the outcome of a potential $M_{\mathrm{W}}>8$ earthquake in Nepal (Q2), before and after the initiation of our education program. Note: ${ }^{*}-$ Multiple answers were possible.

answer itself is not true, and this misinformation could drive people to incorrectly prepare for or act incorrectly during an earthquake. While our efforts clearly decreased this misconception among the students, we could not yet reach each and every student to teach them about the unpredictability of earthquakes. The students who agreed with the impossibility of preventing an earthquake was $86 \%$ in 2020 , showing an absolute increase of $18 \%$ from 2018 . This question also shows that, by 2020 , more than double the respondents participated in disaster risk education training compared to 2018 (Fig. 7).

\subsection{Knowledge and perceptions about how to behave during and after an earthquake}

Three quarters $(75 \%)$ of students in 2020 responded that their family knew what to do and where to go during an earth- quake, which is an increase of $55 \%$ from 2018 . Only $37 \%$ of students in 2020 believed that their home could withstand a large earthquake. For comparison, $65 \%$ students were scared and $22 \%$ panicked during the Gorkha earthquake in 2015 (10\% had calm reactions; $3 \%$ did not care) according to answers in 2018.

In 2018, 62\% of respondents did not know that they should not call others after an earthquake to leave the phone lines available for rescue operations, but in 2020 nearly $80 \%$ of students knew this useful practical point (Fig. 8).

After the implementation of our program, $65 \%$ of the students believed that they could survive if a large earthquake occurred at night, whereas $43 \%$ felt they could survive in 2018. This information reflects more confidence of students as they became familiar with earthquake topics and heard more information about them. 


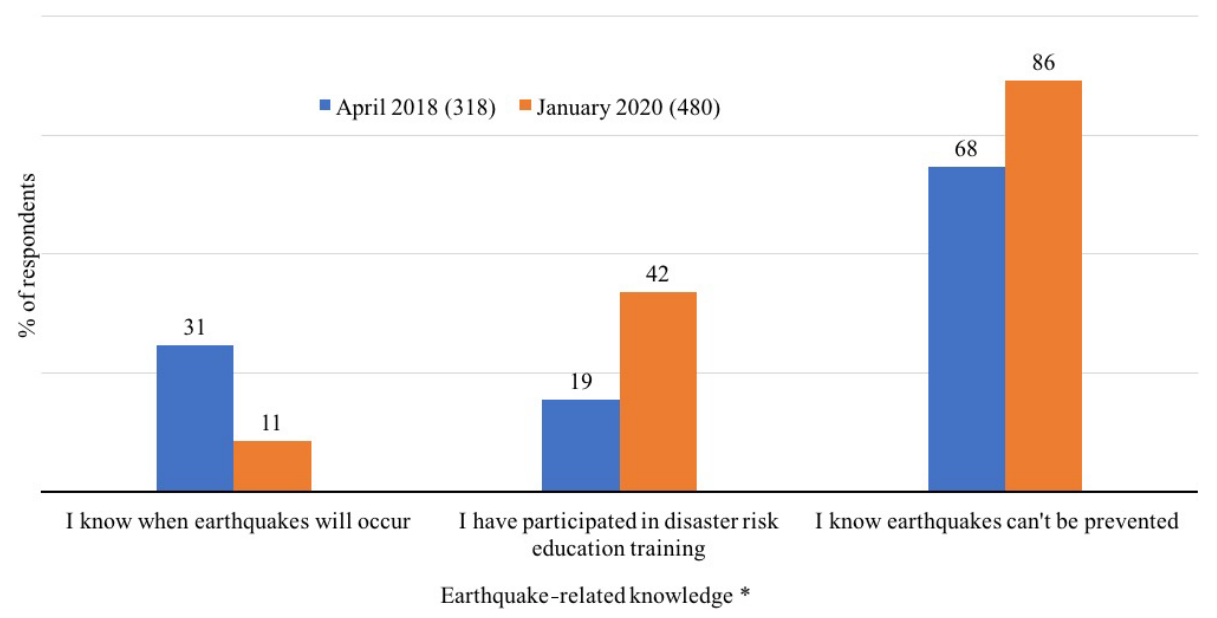

Figure 7. Students' personal knowledge about earthquakes (Q13), before and after the initiation of our education program. Note: * - Multiple answers were possible.

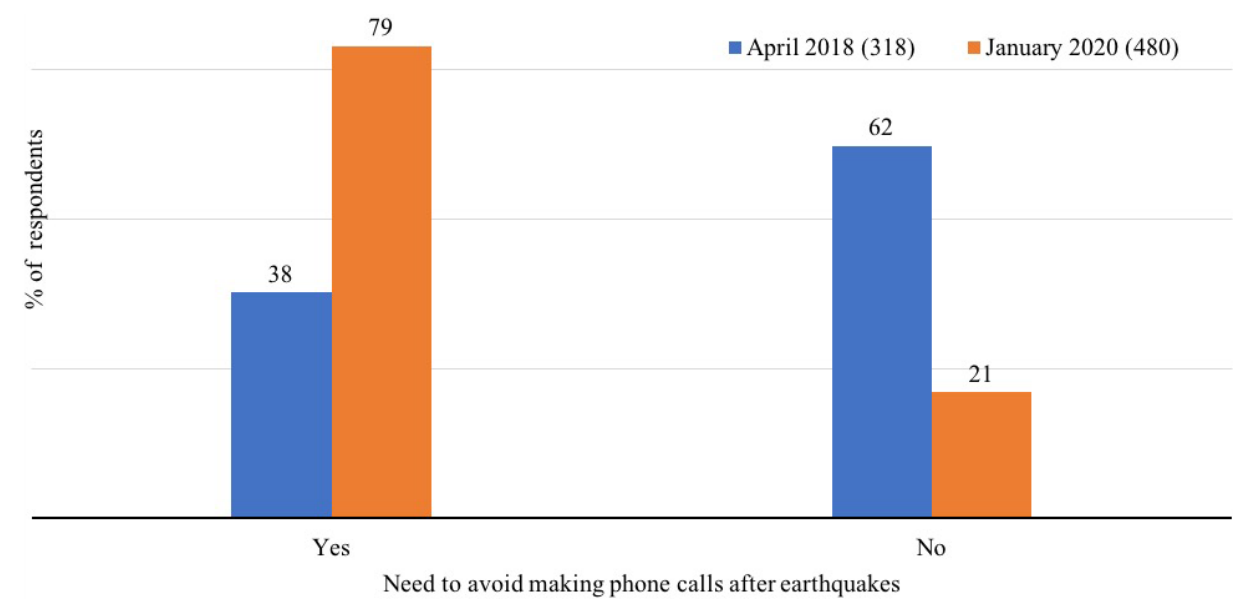

Figure 8. Student's knowledge on the recommendation to avoid making phone calls after an earthquake to leave lines available for rescue operations (Q6), before and after the initiation of our education program. $\left(\chi^{2}=138.72\right.$ and $p$ value $=<0.00001$; the change is significant).

In 2020, $93 \%$ of children knew that, during an earthquake, the majority of injuries and deaths are caused by people being hit by objects through the collapse of constructions; the proportion of people not knowing this dropped by two-thirds after the educational program was implemented. More than two-thirds of the students in 2020 were aware of the additional hazards, such as fires, landslides and floods, that can be triggered by an earthquake. There was a $7 \%$ decrease for this answer since the 2018 survey, but since students who claimed partial knowledge increased by $7 \%$ as well, a net change in knowledge is not really perceptible on this point.

The proportion of students who regularly discuss earthquake-related topics within their families increased by $18 \%$ (absolute increase; see Table 1). This shows that the education program at schools has led to widespread social learning within communities. This is reinforced by the finding that nearly all students (98\%) are interested in learning more about earthquakes in detail, which will aid communities towards having better earthquake preparedness in the long run.

\subsection{Earthquake preparedness and adaptation}

In 2018, $36 \%$ of students perceived that remaining alive during an earthquake depended on luck, while this number has decreased by a relative $60 \%$ after our program started and is a concern for only $21 \%$ of students (Fig. 9). All possible answers regarding adaptation to earthquakes record an increase from 2018 to 2020 (Fig 11). The majority ( $72 \%$ ) of respondents answered that they are aware of the shelter areas and open spaces where they can go in case of an earthquake. The same proportion of people are aware of evacuation areas in 2020, but the increase here is much more important (from $38 \%$ to $69 \%$ ), potentially thanks to the emergency meeting point signs in the Nepali language that we installed at the 
Table 1. Questions and respective answers about earthquake preparedness among students who participated in the surveys, before and after our education program was initiated in central Nepal. Respective statistical indicators are reported in Table S1 in the Supplement.

\begin{tabular}{|c|c|c|c|c|c|c|c|}
\hline \multirow[t]{2}{*}{ No } & \multirow[t]{2}{*}{ Question } & \multicolumn{3}{|c|}{ Answers in 2020 survey } & \multicolumn{3}{|c|}{ Answers in 2018 survey } \\
\hline & & Yes & Partially & No & Yes & Partially & $\mathrm{No}$ \\
\hline Q7 & If a large earthquake occurred at night, could you save yourself? & $65 \%$ & - & $35 \%$ & $43 \%$ & - & $57 \%$ \\
\hline Q8 & $\begin{array}{l}\text { Do you know that the majority of injuries that occur in earth- } \\
\text { quakes are caused by people being hit by or stumbling over } \\
\text { fallen objects? }\end{array}$ & $93 \%$ & - & $7 \%$ & $76 \%$ & - & $24 \%$ \\
\hline Q9 & $\begin{array}{l}\text { Do you know that earthquakes can cause additional damage } \\
\text { such as fire, landslides and floods? }\end{array}$ & $68 \%$ & $21 \%$ & $11 \%$ & $75 \%$ & $14 \%$ & $11 \%$ \\
\hline Q11 & $\begin{array}{l}\text { Preparedness for a major earthquake is the most important } \\
\text { thing. Are you regularly discussing this topic with your family? }\end{array}$ & $71 \%$ & - & $29 \%$ & $53 \%$ & - & $47 \%$ \\
\hline Q12 & $\begin{array}{l}\text { Are you interested in knowing more detail about earthquakes } \\
\text { and how to be prepared? }\end{array}$ & $98 \%$ & - & $2 \%$ & $98 \%$ & - & $2 \%$ \\
\hline
\end{tabular}

schools. The information about which governmental authority to contact after an earthquake is relatively low but has increased by $10 \%$ (absolute). Information about earthquakeprone areas and the reception of knowledge on earthquake disaster adaptation have increased by the factor of 2.5 , from $12 \%$ in 2018 to $31 \%$ in 2020 after the education program.

The relatively small number of respondents who claimed that the government will provide help after an earthquake increased by a factor of almost 3 , from $8 \%$ in 2018 to $23 \%$ in 2020. This percentage is not yet sufficient in general, but the improvement following our program's implementation is noteworthy. Moreover, the level of confidence in the government's reconstruction activities has also grown, from $13 \%$ to $30 \%$, which is a good sign and shows increasing levels of trust. In 2020, $68 \%$ of the respondents knew about the importance of talking about earthquakes with neighbors, friends and colleagues, a nearly two-fold increase in 2 years. Furthermore, we found that all students discussed their new knowledge and learning about earthquakes with the people around them in the community. A total of $91 \%$ of the students had talked to at least some people in the community, only $9 \%$ had discussed this with their parents only, and there is no student who had not had a discussion with others (Fig. 10).

\subsection{Perception of risk}

More than $60 \%$ of the answers showed that students considered the level of seismic risk in their city as medium, which means their risk perception is underestimated with respect to the actual seismic risk level in the region (Stevens et al., 2018). Only every sixth person claims to perceive a high risk, which is clearly less frequent than people declaring low risk. As opposed to our expectations, there is very little change in the level of risk perception in the group of students from 2018 to 2020; the medium risk level group is the same, and there is a minor change in low- and high-risk level groups
(Fig. 12). This result is a surprise, especially when compared to $72 \%$ of respondents in 2020 who believed that there is a more than $70 \%$ chance of experiencing an earthquake larger than the 2015 Gorkha earthquake in their life (Fig. 6a).

\subsection{Project acceptance and future education}

To measure the program's acceptance level, some questions regarding the program itself were also included in the 2020 questionnaire. It was found that $91 \%$ of the students know that a seismometer is installed in their school for earthquake education purposes. A total of $61 \%$ of the students have observed waveforms recorded by the seismometer, either at the school computer (39\%), on the teacher's mobile phone $(18 \%)$ and/or on their parents' or their own mobile phone $(8 \%)$. Furthermore, $85 \%$ of the students answered that teachers teach about earthquakes in the classroom regularly (weekly, monthly, on demand and/or following an earthquake). In 2020, $99 \%$ of the students expressed that they like the earthquake information we have provided to them. Regarding future plans, almost all students are very much $(69 \%)$ or simply $(29 \%)$ interested in learning about earthquakes; this can be achieved by inserting the theme into the official curriculum, which can be instituted by the local, provincial and federal government of Nepal as they all have some field of possible action. Hence, our program and the methods we used for teaching about earthquakes are well accepted.

\subsection{Statistics}

All questions except the last (Question 12 in Table 1; level of interest to learn is $98 \%$ in both surveys) record a clear change in the pattern of answers given following our program's implementation (see Table S1). The biggest statistical change was seen for Question 6 (avoid post-earthquake use of mo- 


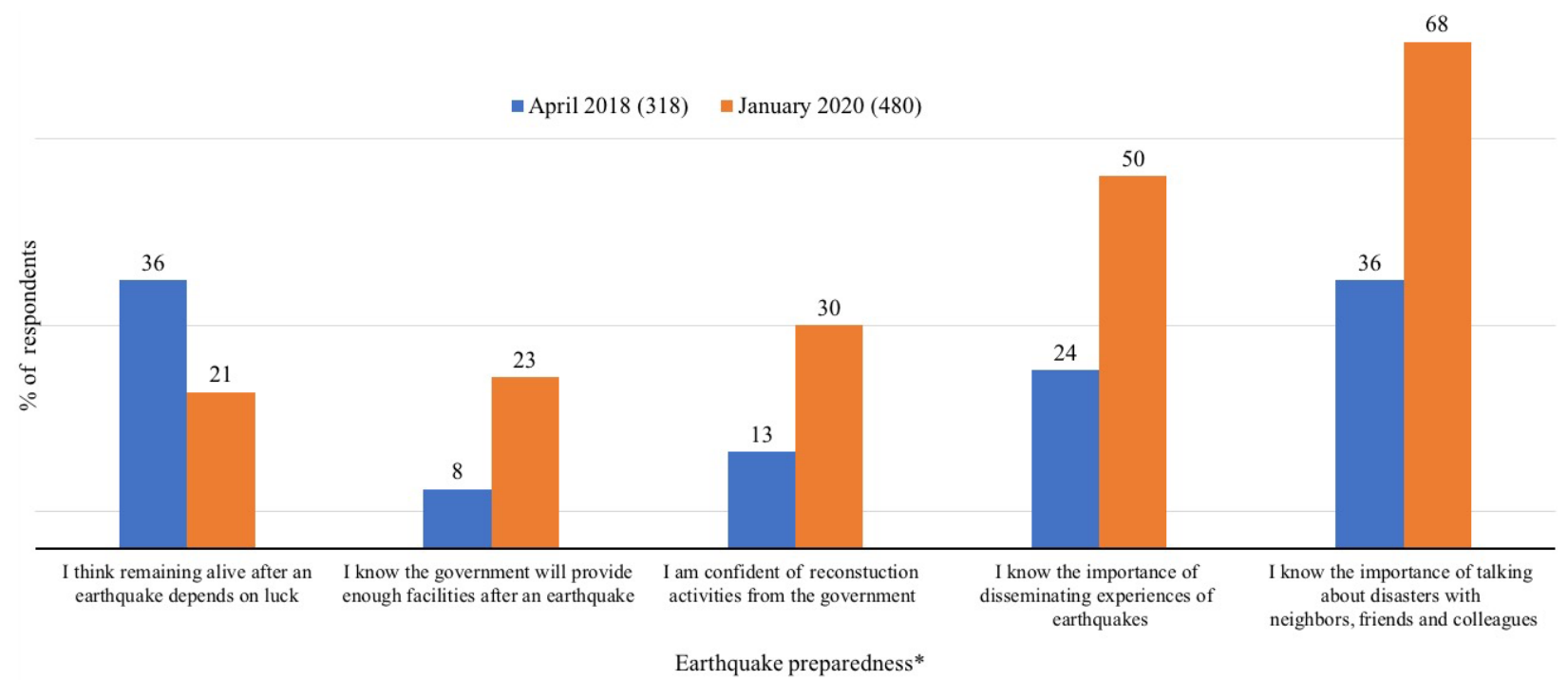

Figure 9. Students' own opinions on earthquake preparedness (Q14), before and after the initiation of our education program. Note: * Multiple answers were possible.

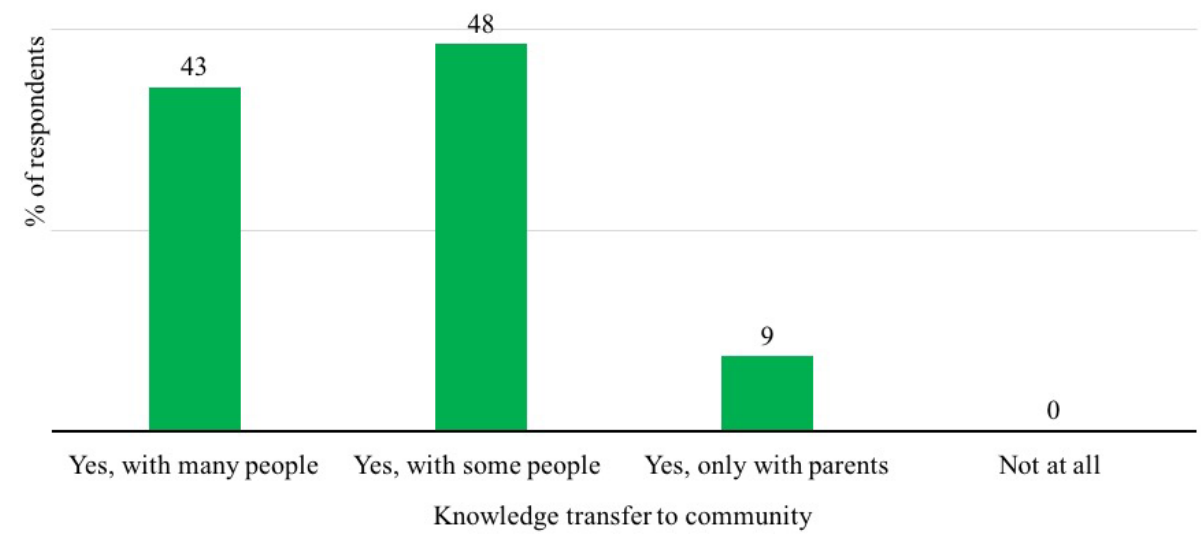

Figure 10. Student activities for transferring the knowledge to the community (question e), after the initiation of our education program.

bile communications), suggesting a big increase in knowledge and very new information. Each question (excluding those with multiple-choice answers) and their corresponding $\chi^{2}$ and $p$ values are reported in Table $\mathrm{S} 1$.

\section{Discussion}

\subsection{Have earthquake awareness levels increased?}

As a result of the novel school-based education program, themes related to earthquakes are more familiar to the students now than in the past, and their awareness levels have increased since the program was initiated. Students know more about earthquake phenomena and have changed their behavior to better prepare for and adapt to forthcoming earthquakes. Earthquake-related knowledge learned by students at schools has also reached the broader community though social learning processes (Reed et al., 2010).

\subsection{Why have the awareness levels increased?}

Beyond the prescribed school education, our program has provided an opportunity for informal and free choice education formats, in which people can learn about topics outside of formal educational settings, which has been well supported by enthusiastic teachers (Falk and Dierking, 2002). 
- April 2018 (318) January 2020 (480)

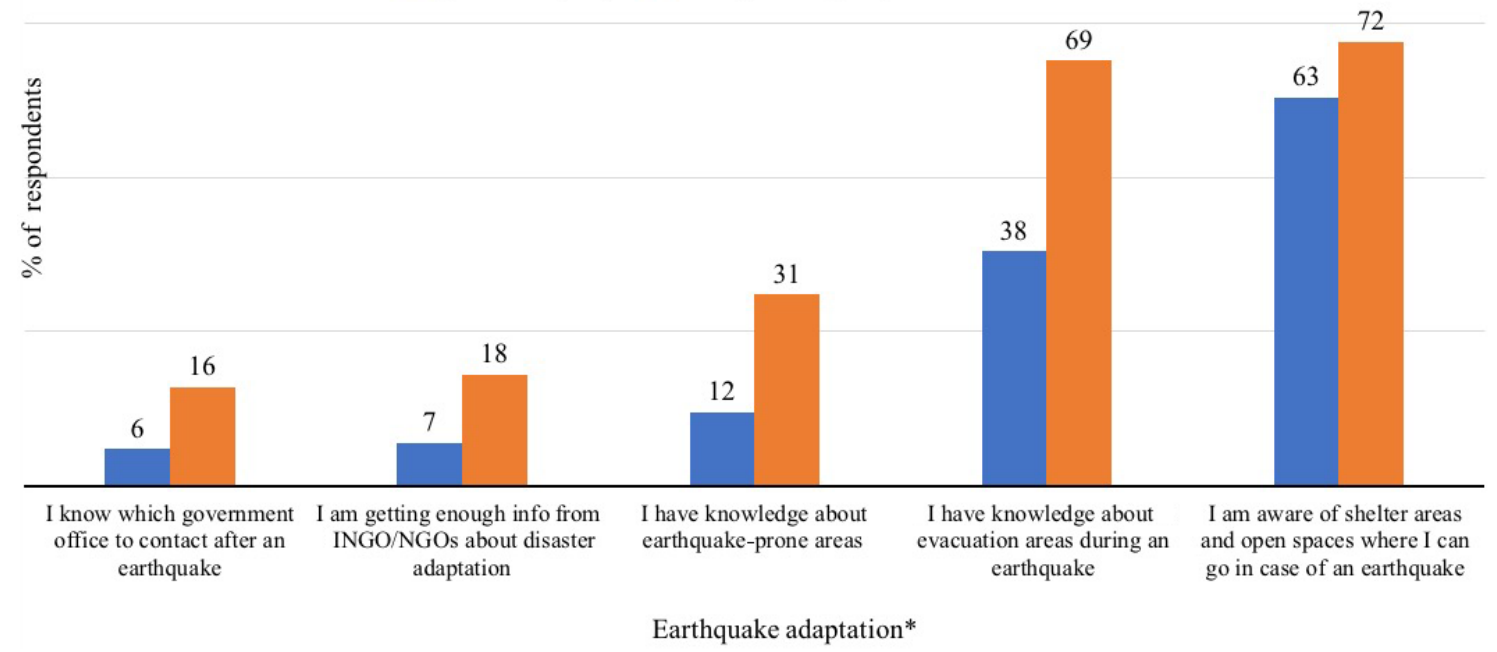

Figure 11. Students' ideas about earthquake adaptation (Q15), before and after the initiation of our education program. Note: * - Multiple answers were possible.

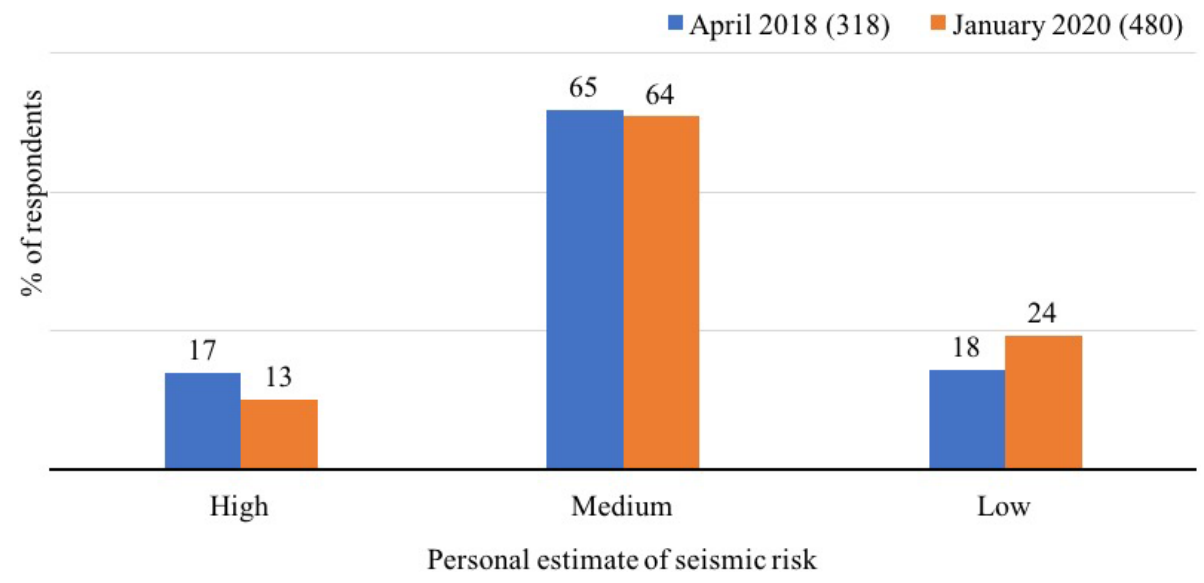

Figure 12. Students' perception of the level of seismic risk in their respective location (Q10), before and after the initiation of our education program. $\left(\chi^{2}=6.33\right.$ and $p$ value $=0.042$; the change is slightly above significant level $)$.

This form of social learning enables an increase in knowledge, and through further communication with others, it spreads knowledge in communities, which may lead to changes in attitudes, behavior and the building of trust in society (Reed et al., 2010). This method is widely applied for the study of natural hazards and its management (e.g., Brody, 2003; O'Keefe et al., 2010). During our program's implementation, despite only being in contact with the school children, the knowledge spread much more widely in local communities through social learning, thus reaching and impacting the original and intended target group.
Peoples' behavior can also be developed through education. The idea is that if people are more informed about earthquakes, then they are more likely to adopt and perform behaviors that will increase their earthquake awareness and preparedness (Hungerford and Volk, 1990). This has similarly been shown for other environmental issues, like invasive species, where campaigns to inform and raise awareness changed behaviors, therefore reducing risk (e.g., Cole et al., 2019).

As a result of our educational program, earthquake-related knowledge has increased, and the behavior necessary to cope 
with earthquakes has also changed. Despite this, the earthquake risk perception of students has not changed greatly yet. Our results show that a realistic and appropriate distribution of earthquake-related knowledge and increased awareness levels are not (or not yet) sufficient to influence the perception of earthquake risk. Perception is a complex phenomenon and can take a long time to change (De Dominicis et al., 2015; Estévez et al., 2015; Cole et al., 2019; Shackleton et al., 2019). Education and awareness raising is a key factor in changing long-term risk perceptions - although programs need to be well tailored to appropriate audiences (Lee et al., 2015). On the other hand, some studies discuss the fact that increased knowledge does not always relate to increased risk perceptions, and increasing perceived risk does not necessarily result in the reduction of risky behavior (e.g., Noroozinejad, 2013; Petros, 2014). In addition, knowing more about a given topic makes people more certain and self-confident, which may lead them to underestimate the related risk (e.g., Stringer et al., 2004). Moreover, increased knowledge and behavior to enable people to adapt and to feel more secure during an earthquake should reduce the fear of the associated risk and, therefore, reduce the risk perception. The limited change in risk perception in this study may be due to better knowledge of the hazard and how to mitigate it (Ndugwa Kabwama and Berg-Beckhoff, 2015).

Hence, how people perceive risk is not necessarily related to the actual risk. We cannot draw a definitive conclusion as to whether the related knowledge can contribute to the amplification or attenuation of the related risk; as such, it could be one of the potential reasons for the low risk perception of people with more knowledge (Reintjes, 2016). Risk perception is thus important for preventative actions, but risk perceptions are often biased (Weinstein, 1988). It could be that more time is needed to change students' risk perceptions, and it is also likely that there are other factors, such as economic status, gender, age group, location of the home in a city, etc., that may influence the level of risk perception of people. A repeated survey in the same age category in a few years' time may give more insight into this question. We suggest that further monitoring and the adaptation of the education system might be needed to better link awareness raising, behavior change and risk perception change.

\subsection{Further action needed}

Since other sources of information, such as newspapers and television, are not easily available to people in the Nepali countryside, we believe that the school is the best platform for transferring knowledge to the community. Proper education at school reaches deep within the families and into the community, and the discussions in those circles are essential for preparing the whole society for future earthquakes. The proportion of students who regularly discuss earthquakerelated topics within their families has increased by $18 \%$ (absolute increase; see Table 1). This shows that the educa- tion program at schools has led to widespread social learning within communities and, possibly, beyond our program's current area. We, therefore, advocate for the continuity of this program and to have education about environmental hazards more deeply embedded in the Nepali education system.

Although this program has increased the earthquake awareness level among students and the broader community in the program area, it alone is not sufficient for seismic risk reduction. Further monitoring and adaptation of the program to promote changes in risk perception and improved learning is advised. Education will help communities to prepare for future earthquakes, but the local, national and regional governments are responsible for the rescue, support and reconstruction operations in the case of a severe earthquake as well as developing and implanting policy to mitigate against threats. Peoples' situations after an earthquake depend on how well they were prepared for the event, so developing policy, for example, on construction quality, depending on expected shaking intensities, is advised. Since the shaking level of an earthquake cannot be controlled, the impact of an earthquake on the community is strongly dependent on the actions taken by the government for its level of preparedness, such as education (so far our program's effort) and, for example, a suitable, locally calibrated and enforced building code. For both aspects, the provincial governments could undertake some of the efforts by drawing on our bottom-up approach and adapting them to maintain earthquake education in schools, which is an efficient way to make earthquakesafer communities. In parallel, local initiatives are encouraged to strengthen these efforts.

\section{Conclusions}

The Seismology at School in Nepal program has been successfully implemented and achieved the aim of raising earthquake awareness and preparedness by educating students in their schools. The program itself, the methods we used for teaching about earthquakes and demonstrations using lowcost seismometers were well accepted by students and teachers. The new knowledge learned by the students at school reaches their parents and is transferred into the local community. The results we observed through two surveys, before and after initiation of the education program, are measurable, statistically significant and show positive changes in earthquake-related knowledge and preparedness levels but not (yet) for the perception of the related risk. A high and positive impact of the program on the students and their communities is encouraging for the continuation and expansion of the program in the region. Governmental institutions are encouraged to build on this experience and develop further policy to mitigate the risk of future earthquakes in Nepal.

Data availability. The data sets used for this study can be made available from the corresponding author upon request. 
Supplement. The supplement related to this article is available online at: https://doi.org/10.5194/gc-3-279-2020-supplement.

Author contributions. The project concept and implementation details were developed by $\mathrm{ShS}$ and GH. Most of the fieldwork was carried out by ShS, with some help from GH. The preparation of the paper, figures, tables and the calculations were done by $\mathrm{ShS}$ and guided and verified by GH and RS. All authors discussed the results and contributed to the final paper.

Competing interests. The authors declare that they have no conflict of interest.

Acknowledgements. We greatly acknowledge the students, school teachers and principals from the schools participating in the program. We are very thankful to the people who helped carry out the surveys. We highly appreciate the American Geophysical Union for their AGU Celebrate 100 grant which allowed us to invite Nepali teachers to the workshop. We also greatly acknowledge the Institute of Earth Sciences and the Faculty of Geosciences and Environment at the University of Lausanne, Switzerland, for hosting Shiba Subedi as a doctoral student and for their support for the necessary instrumentation. The funding from the Federal Commission for Scholarships for Foreign Students, Switzerland, for Shiba Subedi's doctoral thesis is well acknowledged. We warmly thank Anne Sauron, Peter Loader and Paul Denton for their valuable suggestions and useful discussions. We are also thankful to Apsara Pokhrel for translation and typesetting the survey questionnaire into the Nepali language.

Review statement. This paper was edited by Chris King and reviewed by Lok Bijaya Adhikari, John Taber and Michelle Salmon.

\section{References}

Ambraseys, N. and Jackson, D.: A note on early earthquakes in northern India and southern Tibet, Curr. Sci., 84, 570-582, 2003.

Bollinger, L., Tapponnier, P., Sapkota, S. N., and Klinger, Y.: Slip deficit in central Nepal: Omen for a repeat of the $1344 \mathrm{AD}$ earthquake?, Earth Planets Space, 68, 12, https://doi.org/10.1186/s40623-016-0389-1, 2016.

Brody, S. D.: Are we learning to make better plans? A longitudinal analysis of plan quality associated with natural hazards, J. Plan. Educ. Res., 23, 191-201, 2003.

Chaulagain, H., Gautam, D., and Rodrigues, H.: Revisiting major historical earthquakes in Nepal: Overview of 1833, 1934, 1980, 1988, 2011, and 2015 seismic events, in: Impacts and Insights of the Gorkha Earthquake, edited by: Gautam, D. and Rodrigues, H., Elsevier, 1-17, https://doi.org/10.1016/B978-0-12-8128084.00001-8, 2018.

CIESIN and CIAT (Center for International Earth Science Information Network, Columbia University; and Centro Internacional de Agricultura Tropical): Gridded Population of the World (GPW), v3, https://doi.org/10.7927/H4XK8CG2, 2005.
Cole, E., Keller, R. P., and Garbach, K.: Risk of invasive species spread by recreational boaters remains high despite widespread adoption of conservation behaviors, J. Environ. Manage., 229, 112-119, 2019.

De Dominicis, S., Fornara, F., Cancellieri, U. G., Twigger-Ross, C., and Bonaiuto, M.: We are at risk, and so what? Place attachment, environmental risk perceptions and preventive coping behaviours, J. Environ. Psychol., 43, 66-78, 2015.

Dixit, A. M., Yatabe, R., Dahal, R. K., and Bhandary, N. P.: Initiatives for earthquake disaster risk management in the Kathmandu Valley, Natural Hazards, 69, 631-654, 2013.

Dixit, A. M., Yatabe, R., Dahal, R. K., and Bhandary, N. P.: Public school earthquake safety program in Nepal, Geomat. Nat. Haz. Risk, 5, 293-319, 2014.

Estévez, R. A., Anderson, C. B., Pizarro, J. C., and Burgman, M. A.: Clarifying values, risk perceptions, and attitudes to resolve or avoid social conflicts in invasive species management, Conserv. Biol., 29, 19-30, 2015.

Falk, J. H. and Dierking, L. D.: Lessons without limit: How freechoice learning is transforming education, Rowman Altamira, Interciencia, 27, 62-65, 2002.

Godschalk, D. R.: Urban hazard mitigation: creating resilient cities, Nat. Hazards Rev., 4, 136-143, 2003.

Hall, J. C. and Theriot, M. T.: Developing multicultural awareness, knowledge, and skills: Diversity training makes a difference?, Multicultural Perspectives, 18, 35-41, 2016.

Hungerford, H. R. and Volk, T. L.: Changing learner behavior through environmental education, J. Environ. Educ., 21, 8-21, https://doi.org/10.1080/00958964.1990.10753743, 1990.

IRGC: Risk Governance: Towards an Integrative Approach, Geneva, White Paper, No. 1, 2005.

Lee, T. M., Markowitz, E. M., Howe, P. D., Ko, C. Y., and Leiserowitz, A. A.: Predictors of public climate change awareness and risk perception around the world, Nat. Clim. Change, 5, 1014-1020, 2015.

Lehman, D. R. and Taylor, S. E.: Date with an earthquake: Coping with a probable, unpredictable disaster, Pers. Soc. Psychol. B., 13, 546-555, 1987.

National Research Council: A safer future: Reducing the impacts of natural disasters, National Academies Press, Kathmandu, Nepal, 1991.

Ndugwa Kabwama, S. and Berg-Beckhoff, G.: The association between HIV/AIDS-related knowledge and perception of risk for infection: a systematic review, Perspect. Public Heal., 135, 299_ 308, 2015.

Noroozinejad, G., Yarmohamadi, M., Bazrafkan, F., Sehat, M., Rezazadeh, M., and Ahmadi, K.: Perceived risk modifies the effect of HIV knowledge on sexual risk behaviors, Frontiers in Public Health, 1, 33, https://doi.org/10.3389/fpubh.2013.00033, 2013.

NPC: Post Disaster Needs Assessment, Sector Reports, National Planning Commission, Government of Nepal, Kathmandu, 2015.

O'Keefe, G. O. B. P. and Swords, Z. G. J.: Approaching disaster management through social learning, Disaster Prev. Manag., 19, 498-508, 2010.

Petros, P.: Risk perception, HIV/AIDS related knowledge, attitude and practice of the university community: The case of Ethiopian Civil Service College, HIV and AIDS Review, 13, 26-32, 2014. 
Reed, M. S., Evely, A. C., Cundill, G., Fazey, I., Glass, J., Laing, A., Newig, J., Parrish, B., Prell, C., Raymond, C., and Stringer, L. C.: What is social learning?, Ecol. Soc., 15, R1, available at: http://www.ecologyandsociety.org/vol15/iss4/resp1/ (last access: 21 September 2020), 2010.

Reintjes, R., Das, E., Klemm, C., Richardus, J. H., Keßler, V., and Ahmad, A.: "Pandemic Public Health Paradox": time series analysis of the 2009/10 Influenza A/H1N1 epidemiology, media attention, risk perception and public reactions in 5 European countries, PloS one, 11, e0151258, https://doi.org/10.1371/journal.pone.0151258, 2016.

Shackleton, R. T., Richardson, D. M., Shackleton, C. M., Bennett, B., Crowley, S. L., Dehnen-Schmutz, K., Estévez, R. A., Fischer, A., Kueffer, C., Kull, C. A., and Marchante, E.: Explaining people's perceptions of invasive alien species: a conceptual framework, J. Environ. Manage., 229, 10-26, 2019.

Stevens, V. L. and Avouac, J. P.: Millenary $M_{\mathrm{W}} 9.0$ earthquakes required by geodetic strain in the Himalaya, Geophys. Res. Lett., 43, 1118-1123, https://doi.org/10.1002/2015GL067336, 2016.

Stevens, V. L., Shrestha, S. N., and Maharjan, D. K.: Probabilistic Seismic Hazard Assessment of Nepal, B. Seismol. Soc. Am., 108, 3488-3510, 2018.

Stringer, E. M., Sinkala, M., Kumwenda, R., Chapman, V., Mwale, A., Vermund, S. H., and Stringer, J. S.: Personal risk perception, HIV knowledge and risk avoidance behavior, and their relationships to actual HIV serostatus in an urban African obstetric population, Jaids - J. Acq. imm. def., 35, 60-66, https://doi.org/10.1097/00126334-200401010-00009, 2004.
Subedi, S., Hetényi, G., Denton, P., and Sauron, A.: Seismology at School in Nepal: a program for educational and citizen seismology through a low-cost seismic network, Front. Earth Sci., 8, https://doi.org/10.3389/feart.2020.00073, 2020.

Tanaka, K.: The impact of disaster education on public preparation and mitigation for earthquakes: a cross-country comparison between Fukui, Japan and the San Francisco Bay Area, California, USA, Appl. Geogr., 25, 201-225, 2005.

Torani, S., Majd, P. M., Maroufi, S. S., Dowlati, M., and Sheikhi, R. A.: The importance of education on disasters and emergencies: A review article, Journal of education and health promotion, 8 , 85, https://doi.org/10.4103/jehp.jehp_262_18, 2019.

Turner, R. H.: Earthquake prediction and public policy: Disillusions from a National Academy of Sciences report (1), Mass Emergencies, 1, 179-202, 1976.

Weinstein, N. D.: The precaution adoption process, Health Psychol., 7, 355-386, https://doi.org/10.1037/0278-6133.7.4.355, 1988. 